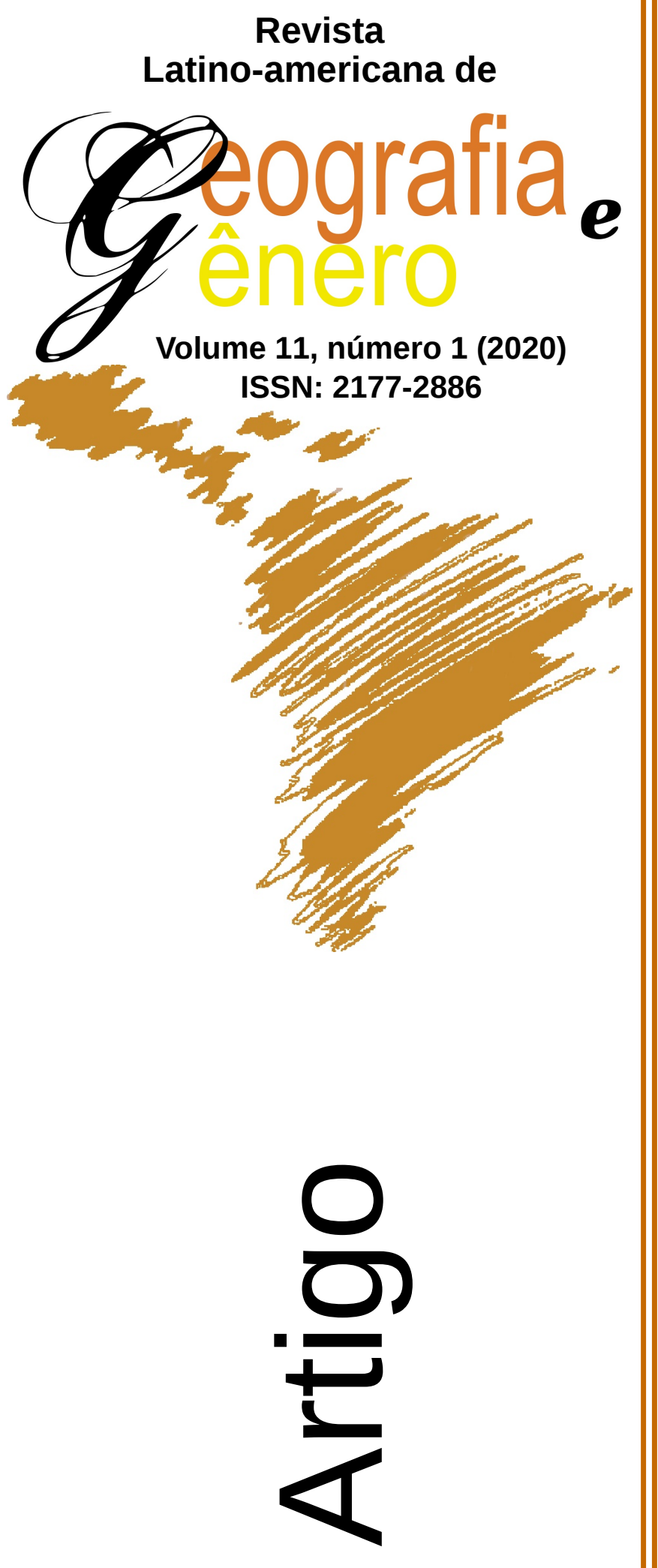

Dinâmicas Psicossociais do Trabalho das Zungueiras Angolanas

Dinámicas Psicosociales del Trabajo de las Zungueiras Angoleñas

Psychosocial Dynamics of the Work of Angolan Zungueiras

Felizardo Tchiengo Bartolomeu Costa Escola Superior Pedagógica do Bengo - Angola felicosta_4@hotmail.com

Como citar este artigo:

COSTA, Felizardo Tchiengo Bartolomeu. Dinâmicas Psicossociais do Trabalho das Zungueiras Angolanas. Revista Latino Americana de Geografia e Gênero, v. 11, n. 1, p. 03 - 19, 2020. ISSN 2177-2886.

Disponível em:

http://www.revistas2.uepg.br/index.php/rlagg 


\title{
Dinâmicas Psicossociais do Trabalho das Zungueiras Angolanas
}

\author{
Dinámicas Psicosociales del Trabajo de las Zungueiras Angoleñas \\ Psychosocial Dynamics of the Work of Angolan Zungueiras
}

\begin{abstract}
Resumo
"Zungueiras" é o nome dado, em Angola, às mulheres que trabalham como vendedoras ambulantes, percorrendo as cidades e oferecendo diferentes produtos. Com o objetivo de compreender o cotidiano e os desafios das "zungueiras", foi realizada uma pesquisa na cidade de Lubango, província de Huíla, utilizando a etnografia como recurso metodológico. Foram realizadas imersões no universo da zunga mediante o acompanhamento do trabalho de seis zungueiras. Nesse acompanhamento foram realizadas observações e entrevistas, gravadas e registradas num diário de campo. Foi possível constatar que o trabalho das zungueiras exige uma intensa mobilidade e é exercido de forma extremamente informal e precária, sem qualquer amparo legal e reconhecimento pelas autoridades municipais ou de esferas maiores. Além da precariedade, as zungueiras são criminalizadas e perseguidas por fiscais municipais e objeto de preconceito e forte rejeição por serem consideradas uma presença indesejável na cidade, um atentado contra a estética de uma cidade que persegue os ideais do urbanismo moderno.
\end{abstract}

Palavras-Chave: Angola; Zungueira; Trabalho Informal.

\section{Resumen}

"Zungueiras" es el nombre dado, en Angola, a las mujeres que trabajan como vendedoras ambulantes, recorriendo las ciudades y ofreciendo diferentes productos. Para comprender la vida cotidiana y los desafíos de las zungueiras, se realizó una investigación en la ciudad de Lubango, provincia de Húla, utilizando la etnografía como recurso metodológico. Las inmersiones se llevaron a cabo en el universo zunga al monitorear el trabajo de seis zungueiras. En este monitoreo, se llevaron a cabo observaciones y entrevistas, grabadas y registradas en un diario de campo. Fue posible verificar que el trabajo de las zungueiras requiere una movilidad intensa y se lleva a cabo de una manera extremadamente informal y precaria, sin ningún apoyo legal y reconocimiento por parte de las autoridades municipales o de las esferas más grandes. Además de la precariedad, los inspectores municipales criminalizan y persiguen a las zungueiras, quienes son objeto de prejuicios y un fuerte rechazo por ser consideradas con una presencia indeseable en la ciudad, un atentado contra la estética de una ciudad que persigue los ideales del urbanismo moderno.

Palabras-Clave: Angola; Zungueira; Trabajo Informal.

Abstract

"Zungueiras" is the name given, in Angola, to women who work as street vendors, touring the cities and offering different products. In order to understand the daily life and challenges of the "zungueiras", a research was carried out in the city of Lubango, Huíla province, using ethnography as a methodological resource. Immersions were carried out in the zunga universe by monitoring the work of six zungueiras. In this monitoring, observations and interviews were carried out, recorded and registered in a field diary. It was possible to verify that the 
work of the zungueiras requires intense mobility and is carried out in an extremely informal and precarious way, without any legal support and recognition by the municipal authorities or larger spheres. In addition to the precariousness, the zungueiras are criminalized and persecuted by municipal inspectors and they are object of prejudice and strong rejection for being considered an undesirable presence in the city, an attempt against the aesthetics of a city that pursues the ideals of modern urbanism.

Keywords: Angola; Zungueira; Informal Work.

\section{Introdução}

A zungueira é apresentada por Santos (2011) como se tratando de um jargão utilizado pelos luandenses para designar os operadores dessa nova situação do comércio de rua, pois o termo zungueira tem a sua origem etimológica na palavra zunga, expressão da língua nacional kimbundu que, literalmente traduzida para o português, significa andar à volta, girar.

Portanto, a palavra zunga é usada para caracterizar aquelas vendedoras ambulantes que circulam pela cidade vendendo diversas mercadorias. Em Angola, as mulheres têm forte presença na zunga, tal como em outras formas de comércio de rua.

A história das mulheres em Angola possui muitos pontos em comum com mulheres de outros países e continentes, mas também guarda algumas especificidades.

Uma dessas especificidades diz respeito à guerra de independência desse país que durou 37 anos e se encerrou em 2002.

Durante a guerra as raparigas tinham difícil acesso à educação formal e eram normalmente direcionadas para as atividades domésticas. Forçadas por várias formas de desigualdade elas apresentavam uma taxa de desistência escolar de cerca de 29\%. Em 1997 entre os adultos (mais de 19 anos), 43\% das mulheres nunca haviam frequentado a escola e apenas $18 \%$ das mulheres estudaram para além da $4^{\text {a }}$ classe em contraste com $37 \%$ dos homens. Entre os idosos (mais de 65 anos) os homens tem uma probabilidade $150 \%$ maior de saberem ler e escrever (PEREIRA, 2015).

O Diagnóstico de Gênero de Angola (AFONSO \& CAETANO, 2015) sustenta que existem muitas mulheres sem documentos, dificultando inclusive o seu acesso a programas de microcrédito destinado a esta população. Em alguns casos, as mesmas usam, por não possuirem bilhete de identidade (RG), um homem/parceiro como intermediário. Tendo sido relatadas histórias de mulheres nessa situação que acabam por pagar uma 'comissão' aos intermediários.

Neste sentido, as zungueiras seriam mais uma personagem deste cenário e como defendem Afonso e Caetano (2015) a imagem do mercado informal, ocupando o degrau mais baixo da informalidade. Vender na rua seria o último recurso, portanto, sem quaisquer condições de trabalho e atingidas pela repressão policial, mas reagindo como podem para permanecerem na atividade e em condições diferentes das quitandeiras - vendedoras estabelecidas nos mercado -, que dispõem de condições melhores, especialmente naqueles que foram reabilitados. 
[...] A guerra civil exigiu das mulheres maior dedicação às atividades de reprodução em detrimento das atividades de produção econômica. As suas vidas foram ainda transformadas indiretamente pela guerra em diversos aspectos: na sua integridade física (por exemplo, ao sofrerem acidentes ao terem de trabalhar nos campos agrícolas intensamente minados), com a morte de familiares, na sua educação e na dos seus filhos, nas atividades produtivas e profissionais, por meio dos processos de migração forçada do campo para a cidade (AFONSO \& CAETANO, 2014, p. 9).

Contudo, a despeito da sua contribuição altamente relevante elas ainda assim foram apagadas das negociações subsequentes. O Estado eximiu-se da sua responsabilidade de promover a reintegração, mas também de fomentar a criação de novas oportunidades para as mulheres angolanas, sendo que muitas delas se viram empurradas para o sector informal, que acabou sendo também, seu único espaço possível de sustento.

O Estado Angolano criou estruturas oficiais que serviriam de suporte à integração das mulheres, sobretudo aquelas que se encontram em situação de vulnerabilidade, ainda assim, como nos diz Pereira (2015), a existência de tais estruturas não significou realmente a priorização das questões de gênero. Ações desenvolvidas pelo Ministério da Família e Promoção da Mulher (MINFAMU) são limitadas e parecem não alterar a realidade das mulheres angolanas, apesar do constante apoio da comunidade internacional aos projetos desenvolvidos por este Ministério. Além disto, o mercado de trabalho não é uma área tida como prioritária nas ações do MINFAMU, estando essencialmente focado nas questões da família, violência (orientação jurídica) e da saúde da mulher (HIV-SIDA, nutrição, cuidados maternos, etc.).

Segundo Liberato (2016) a guerra civil forçou as mulheres a substituírem os companheiros no sustento, quando eles foram levados para o cumprimento do serviço militar obrigatório. Apesar disso, elas não conseguiram espaço no setor formal de trabalho, pois o seu baixo nível de alfabetização e a inexistência de uma indústria de manufatura desenvolvida empurraram-nas para os setores informais rurais e urbanos da economia.

A limitação das oportunidades de emprego nas áreas urbanas e o aumento da procura por trabalho causado por todas as vagas de migração, continuou a afetar sobretudo e de sobremaneira a camada mais vulnerável no seio do mercado de trabalho - as mulheres, que constituem a maioria da população angolana e exercem um importante papel na economia nacional, sendo que cerca de $27 \%$ dos agregados familiares angolanos são chefiados por mulheres (...), ainda que mais da metade das mulheres chefes de agregados familiares angolanos sejam analfabetas. Em 2002 as mulheres ocupavam 63,5\% dos empregos no setor informal e $33 \%$ no setor formal. As barreiras prováveis para a inserção das mulheres no mercado de trabalho são barreiras formais de gênero como no exército, barreiras formais indiretamente tendenciosas tal como a educação formal, barreiras combinadas formal/informal tais como regulamentações rígidas no 
que diz respeito à gravidez e acompanhamento da criança, barreiras informais incluindo tanto uma rígida regulamentação como opiniões tendenciosas de gênero (PEREIRA, 2015, p. 4 - 5)

A entrada em cena das zungueiras faz parte de um panorama que tende a aproximar à figura da zungueira à da quitandeira, que já era presente na época colonial.

\section{Das quitandeiras às zungueiras}

De acordo com Santos (2011, p. 58), “(...) a presença de 'mamães quitandeiras', zungueiras, peixeiras e kinguilas nas ruas de Luanda, evidencia uma tradição que confere um lugar de destaque às mulheres de rua no imaginário social luandense". Elas tratam de reinventar uma forma de trabalho informal antiga, da qual as quitandeiras são as precursoras, como refere Lopes (2007, p. 29), "tal como sucede em relação aos mercados, a presença das quitandeiras a percorrer as ruas da cidade é uma imagem que se confunde com a própria história de Luanda".

Vale dizer que tal qual a quitandeira, a zungueira colonizou o país com a sua presença no quotidiano angolano. "Elas são, portanto, o legado das quitandeiras na Angola moderna, são a adaptação do trabalho tradicional daquelas mulheres às novas demandas sócio-econômicas (PANTOJA, 2008, p. 136)". Hoje encontramo-las em toda a extensão do território, ainda que nem sempre com as mesmas características, ou seja, as mercadorias que comercializam são muito diferentes, a forma como as adquirem também podem variar muito. Possuem trajetórias pessoais e familiares nem sempre coincidentes e seus desafios e sonhos também são diversos. A sua percursora vivia em um tempo diferente.

A quitandeira era vista como uma mulher de negócios, apesar de pequenos e informais, e usava essa sua habilidade para trocar, comprar e vender as mercadorias de que dispunha, às vezes vendendo a crédito aos vizinhos e amigos sem muita discriminação dos produtos que comercializava. Pelo menos é assim que Batalha (1889, citado por LOPES, 2007) via estas mulheres.

Santos (1967, citado por LOPES, 2007) fazia igual referência a diversidade de produtos negociados por elas, referindo a venda da cola, gengibre, ovos e galinácios, frutas e sarrabulho. Com o passar do tempo, a instauração e oficialização de vários mercados (abertos) antes ilegais, fizeram as quitandeiras deixarem de circular.

Elas fazem parte de uma história que faz diluir a sua atividade com o surgimento dos mercados ao ar livre organizados pela administração colonial. Venâncio (1997, citado por LOPES, 2007) que fala sobre a existência de uma rede alargada de mercados oficiais em 1992. Os mesmos eram controlados pelo Estado com pagamento de taxas de ocupação de espaço, licenças para exercício da atividade e alguma fiscalização econômica e sanitária. Contavamse cerca de 26 mercados, com mais de 200 operadores, ativos em Luanda.

As quitandeiras permitem-nos compreender ao menos em parte a dinâmica social e comercial de Luanda, ligadas intrinsecamente à antiga estruturação econômica da capital, uma vez que eram responsáveis pelo abastecimento da 
cidade e dos navios negreiros, e o elo entre a produção, no interior da província, e a distribuição urbana (QUEIROZ, 2016).

Assim, historicamente a zunga toma o lugar deixado pela antiga quitandeira, quando os mercados começam a tornar-se uma opção difícil, com a grande concentração de agentes e com o aumento da concorrência nos mesmos, causando a partir da década de 1990 a popularização das zungueiras, maioritariamente do sexo feminino, mas também de zungueiros, além de jovens e crianças (LOPES, 2007).

Considerando que as zungueiras são, por assim dizer, netas das quitandeiras, elas herdaram também alguns dos principais obstáculos com que já haviam se deparado suas antecessoras, dentre eles, a sua negação tanto pelo Estado, quanto pela sociedade. Ou seja, da mesma forma que tal como nos contam Pantoja (2008) e Santos (2011), as quitandeiras tornaram-se um incômodo no projecto de modernização e remodelação da cidade no fim do século XIX, quando os mercados foram construídos, as zungueiras também têm sofrido constantemente com a importunação dos órgãos governamentais. Por meio de acções repressivas, caracterizadas por extrema violência e sem que possam usufruir de qualquer tipo de proteção, sem direitos e garantias sociais. Deste modo, elas revivem o mesmo martírio sofrido por suas ancestrais, obrigadas a trabalharem forçadamente às margens da lei (SANTOS, 2011), vítimas de um projeto higienista de elites africanas ocidentalizadas.

\section{Objetivo da pesquisa}

O principal objetivo deste trabalho é fazer uma imersão no universo do trabalho das zungueiras, utilizando a etnografia, para estabelecer categorias de análise que permitam compreender as dinâmicas psicossociais desta atividade, seus desafios, problemas e contradições.

\section{Metodologia}

A realização desta pesquisa foi orientada, metodologicamente, pela etnografia, tal como propõem Sato e Souza (2001) o uso da etnografia na psicologia (etnografia psicológica). Baseadas em Wolcott (1987), as referidas autoras entendem que a etnografia, enquanto uma metodologia transdisciplinar, é útil à psicologia possibilitando adentramentos de experiências concretas e cotidianos, relativamente desconhecidos, vividos por pessoas e coletividades num determinado espaço e tempo.

Consideramos importante investigar a atividade da zunga, especificamente na cidade do Lubango, penetrando o quotidiano constituído pelo trabalho das mulheres conhecidas por zungueiras, realizando nossas observações, entrevistas, coletando depoimentos e histórias de vida.

A observação e a escuta foram ferramentas importantes, tal como já acontece no seio das sociologias interpretativas, como salientam Sato e Souza (2001), esta situação permite, também, um afastamento do funcionalismo e do estruturalismo em direção à interação efetiva com as análises das relações cotidianas, que permeiam aspectos tanto particulares quanto globais da história dos sujeitos e das realidades em que se inserem. Tornam-se, deste modo, o 
local e o particular, espaços para o trabalho empírico, onde processos gerais possam ser descritos e compreendidos e construídas teorias.

Contudo, este trabalho não pretende ser uma tradução da voz das zungueiras, ao contrário, é uma tentativa de captar aquilo que poderíamos construir por meio da interlocução com elas, desejando estabelecer um ponto de partida que nos permitisse olhar para o campo com a singularidade que o mesmo exige.

\section{Participantes}

Esta pesquisa realizou-se em 2017, durante os meses de Janeiro à Março no Lubango, município sede da província da Huíla (Angola), com cerca de 2 milhões de habitantes. Desenvolveu-se a partir da colônia de Sá da Bandeira, tomando esse nome entre 1884 e 1975. É constituído pelos distritos de Lubango, Arimba, Hoque e Huíla e habitada por diferentes grupos étnicos (vanyaneka-nkumbi, ovimbundu, vangangela, tucokwe, bakongo, vambinda, ambundu, e oviwambo).

Foi implantada no território do antigo Rei Kaluvangu, cujo pequeno reino estava na aldeia conhecida hoje como Muholo. Foi elevada à categoria de cidade no dia 2 de Setembro de 1901, com o nome de Sá da Bandeira (Coimbra de Angola).

O trabalho de campo esteve apoiado na observação não-participante e na etnografia psicológica. Participaram da pesquisa 6 zungueiras. O contato com as mulheres foi feito na rua, que é o seu local de trabalho. Durante esses contatos era frequente elas nos sugerirem os pontos da cidade em que podíamos encontrar outras mulheres com quem conversar.

\section{Discussão dos resultados}

No decurso das nossas vivências e observações, verificamos uma gama diversificada de práticas que consideramos estarem inscritas na zunga. As mais relevantes agrupamo-las nas seguintes categorias apresentadas a seguir:

\section{Gestão familiar do desemprego e as trajetórias de trabalho}

Esta categoria expressa a constatação, pelas entrevistas, de uma característica muito própria das zungueiras. Por um lado, o seu trabalho era quase uma praga familiar e por outro, uma forma de gestão da própria situação de pobreza, precariedade e desemprego familiar. Constitui-se, assim, uma experiência compartilhada de trabalho, mas sobretudo, de sofrimento.

Saltam à vista, por exemplo, seus relatos sobre o tempo que trabalham como zungueiras, umas tendo iniciado mais cedo e outras mais tarde.

Já zungava memo desde há muito tempo, mesmo, já zungo memo aqui na cidade, zungava banana, agora é que é que entrei na roupa E3.

Começou como fiquei grávida. [...]Mas já vendia desde pequena, vendia fardo na praça do João [Mercado João de Almeida]E10 
O facto de a zunga ser uma espécie de tradição familiar, também é importante, porque com a herança deste trabalho, vêm também a precariedade, o trabalho pesado, a pobreza e várias outras formas de subalternização. Algumas aprenderam com as mães, quando ainda eram estudantes.

Eu vendia com a minha mãe, quando a minha mãe se mudou para Luanda, a minha mãe me deixou como o negócio e decidi entrar na zunga. Era mesmo estudante E5.

Outras fazem da atividade, de fato, um negócio familiar onde cada uma especializa-se em vender coisas diferentes das mercadorias vendidas pelas outras mulheres da família. Desta forma também se entrecruzam trajetórias de irmãs, primas, sobrinhas e tias:

Tem as minhas primas, minhas sobrinhas, minhas primas E5.

Ao que parece, a solidariedade familiar característica das famílias angolanas se estende à experiência de trabalho, ainda que precário. Neste sentido, é possível que o compartilhamento do quotidiano com alguém conhecido, torne menos penoso o seu sofrimento.

Sim, tem. Tem essa minha irmã que andei com ela mais umas que ficam no João [Mercado João de Almeida], mais outras que também ficam lá. Tenho 5 irmãs. E6

As 3 vendem perfume na zunga, nós as duas é que vendemo isso aqui [frutas]. E6

A minha irmã vende peixe também comigo, a outra vende fruta.

... Elas é que começaram a vender mais primeira que eu. E8

Sim, tem, minha sobrinha, 1 anos. [vende] Peixe!E7

O que vendem? Um pouco de tudo, mas ao que parece, a escolha do que vender também pode ser uma decisão motivada principalmente pela acessibilidade dos produtos e a facilidade de vendê-los, daí a preferência por comidas, roupas e outras mercadorias de uso comum.

Na família também são zungueiras. Zungam fruta e bananas. E3

Monteiro (2012) refere, também a constante alternância dos produtos comercializados. Supostamente, essa seria muito maior entre as zungueiras, do que era entre as quitandeiras.

A presença de familiares e sobretudo mulheres parece grande, como nos diz uma das entrevistadas.

...Ah, não falta minha irmã, quase a maioria, é zungar, quase a maioria... E9

Fica visível que a questão da entrada para a zunga está relacionada às trajetórias familiares. Quanto mais pobres as famílias, maiores parecem as possibilidades de entrarem para este território, quanto mais zungueiras na família, tanto maiores as possibilidades de as jovens mulheres também 
Dinâmicas Psicossociais do Trabalho das Zungueiras Angolanas

enveredarem por este caminho. Contudo, o que têm de comum nessas trajetórias, mais do que o laço sanguíneo, é com certeza a situação de pobreza familiar. Fazendo da zunga um dispositivo de gestão da pobreza e desemprego familiar.

\section{Empreendedorismo predatório ou Privilégio da sobrevivência?}

Nesta categoria agrupamos os dados que nos apresentaram uma faceta extremamente melindrosa da zunga. A transformação da zungueira em mais uma vítima dos processos contemporâneos de precarização no trabalho, algo já por demais debatido nas discussões sobre as consequências do capitalismo contemporâneo, como o fazem por exemplo Costa, Justo e Freitas (2016). A perniciosidade é tal que as mulheres se veem em uma situação de aprisionamento cíclico. É o caso, por exemplo, da cobrança abusiva de juros.

Tudo começou mesmo assim. Emprestos [empréstimos]. Epá mana me empresta só 5000, e às vezes o 5000 vão te pedir quê? Juro. Você às vezes entra com juro. 5000 para 7.500 e você tem que trabalhar mesmo, tem que zungar mesmo, afiar os pés para poder... às vezes tem que aceitar um juro, porque se não aceite, não tem dinheiro para zungar, ninguém te dá. Mas com juro, é rápido. E9

Outro bom exemplo dessa perniciosidade é o caso dos kilapis ${ }^{1}$ que se fazem para obter as mercadorias, as mulheres que trabalham vendendo o fardo ${ }^{2}$ apresentam os seguintes relatos.

Até essa roupa também só tiramo nas pessoas que tem fardo, vamo fazê kilapi, vendemo e levamo o dinheiro da Sra.

Não tem muito problema... e casaco, às vezes você passa todo dia, até de tarde você no vende nem nada. Nas Sras que abrem os atados. Abrem e nós tiramos os casacos e viemo zungar aqui na cidade. E2 Te dá negócio para ir vender, você ganha lá bocado. E3

Os lucros obtidos nem são por isso fabulosos, apesar dos preços praticados, já que boa parte do dinheiro vai para a dona dos balões de fardo.

Depende dos casacos, das vezes ganho 5000, 4000, depende só, varia. [inaudivel] Aqui memo no jardim, no jardim no milênio. E3

Se o negócio das zungueiras é muitas vezes apresentado nos discursos oficiais, como exemplo de espírito empreendedor, o que os dados nos sugerem é que na verdade, pelo menos no caso das mulheres entrevistadas, tal não passa de um empreendedorismo predatório, que serve para as escravizar. Exploração muitas vezes levada à cabo por familiares próximos, tal como nos diz uma de nossas entrevistadas, que está no negócio de bolinhos (doces).

1 Levar um produto por consignação, ou a crédito.

2 Roupa usada. 
Dinâmicas Psicossociais do Trabalho das Zungueiras Angolanas

...É da minha mana, eu vendo para ela, sábado é meu dia e o dinheiro é meu. Uma semana o dinheiro é dela e sábado o dinheiro é meu! E7

Sobre o questionamento, por que estas mulheres se submetem a essas situações e muitas outras? A resposta vem nas suas próprias palavras de forma simples.

É onde que tamo a tirar o nosso pão. E2

$O$ meu trabalho? é memo zunga casaco. E3

É mesmo assim, não tem como. Se não zungar, não tem coisa para dar na criança. E7

Ou seja, a sobrevivência, que para elas se tornou um verdadeiro privilégio, é o mote dessa subordinação. Sem instrumentos que permitam lutar de modo mais efetivo contra as injustiças sociais a que a sua situação as obriga, elas submetem-se, pelos filhos, pela família ou pelos sonhos que já não têm sequer o direito de ter e na esperança de que o governo retome seu papel de garantidor dos direitos sociais básicos (emprego, educação, saúde).

O governo? Eu peço, quando... só emprego, porque aqui na zunga cansa. Primeira coisa, esse negócio que faço, a vender, não é nosso, é alheio. Te dá negócio para ir vender, você ganha lá bocado. Lá em casa as crianças precisa come também bem, precisa muitas coisa. Nas matrícula, tudo precisa. E3

\section{Por quê zungar?}

O questionamento que esta categoria traz, serve essencialmente dois propósitos: razões objetivas do trabalho da zungueira (garantia de sustento) e seu conteúdo paradoxalmente emancipatório. Sobre o primeiro, restam poucas dúvidas, zungar é procurar sobreviver, elas zungam para não morrer, zungam porque não têm emprego, zungam porque precisam de desenrascar-se, pois ficar parada é inaceitável.

... não, a zunga é só para desarrascar a nossa vida, para no fica só em casa, a sentar, a esperar, o outro, tem também que desarrascar um pouco, porque no temo emprego.

Eu no fazia nada.E6

Sobre o segundo, estas mulheres zungam porque procuram emancipação, pois sem a zunga, seriam pessoas vivendo em total dependência de outros, simples seres assujeitados, sem poderem ter qualquer autonomia. Neste sentido ir à zunga é procurar sua independência e autonomia em relação à mãe, ao pai, aos maridos, namorados, enfim, romper com subalternizações primárias. Pela zunga elas encontram o caminho para a cidadania e este é de certo modo um dos grandes paradoxos da zunga, que é pelo caminho espinhoso da subalternização, da exploração pelos juros abusivos, pelo exercício de uma atividade extremamente precarizada e pela via de um empreendedorismo de subsistência que elas buscam e às vezes encontram a sua emancipação. 
Entrei para a zunga só para não depender da minha mãe, preciso de muita coisa. A minha mãe também vende coisas que nem dá para lhe pedir, nem dá para pedir coisas que eu quero, por isso que entrei na zunga só pra mim poder ter a minha coisa e também ajudar a minha mãe... É mesmo assim, não tem como. Se não zungar, não tem coisa para dar na criança. E7

Nenhuma delas zunga por capricho, como vimos, mesmos as mais novas, zunga responsavelmente, porque a zunga é coisa séria, é trabalho penoso, sofrível e doloroso a zunga é andar até se cansar.

A zunga, o trabalho da zunga é andar muito. No mercado não tem cliente, a gente tem que andar, procurar os clientes, se você fica só no mercado, há as pessoas que ficam fora do mercado, você que vende lá dentro, você não consegue vender desde manhã até à tarde, você volta mesmo em casa, não vendeste nada. A pessoa tem que girar, sair mesmo daqui ao Cristo rei, na senhora do monte, a vender para você vender só alguma coisa para comprar alguma coisa para a tua filha, sabão, Omo, medicamento... E10

Quem não gosta de trabalhar, quem gosta de comodidade, não zunga, ou faz algo menos desgastante, algo que castigue menos o corpo. As zungueiras giram toda a cidade, todos os dias e não por puro gozo. Porque zungar dói:

Só das minhas pernas a doer, o corpo a doer, não tamo a consegui nada na vida,(...). E2

Estas mulheres precisam de trabalhar, tendo que passar a maior parte do dia, andando pela cidade, 'na zunga', procurando vender os produtos, que carregam na cabeça e andando a pé, por grandes distâncias, independentemente do clima, pois, parar significa não ter nada para oferecer aos filhos, que dependem daquele esforço insalubre da mãe zungueira.

\section{A cidade (é) proibida ou um projeto de higienização? Sofrimento, perseguição e violência}

Inicialmente esta categoria havia sido interpretada de modo fragmentado, considerando que a questão da cidade e da higienização estavam apartadas da questão do sofrimento. Contudo, uma análise mais cuidada dos dados, demonstrou que o ideal seria tratá-la como uma única categoria, que precisava ser entendida dentro de sua complexidade natural.

A discussão levantada nesta categoria recoloca a questão da produção do espaço social pelas zungueiras. Provocando-nos a perguntar, por exemplo, que espaço é esse do qual se quer eliminar qualquer vestígio das zungueiras? Novamente, uma hipótese já foi apresentada anteriormente. Os nossos dados do campo, apenas avolumaram os fundamentos para sustentar tal hipótese.

Infelizmente, os principais agentes de tal limpeza sectária, no caso da zunga são agentes públicos, essencialmente os agentes dos serviços comunitários e algumas vezes com apoio da polícia. Com a operação resgate realizada pelo 
estado com o pressuposto de moralizar a sociedade e formalizar a economia informal, a virulência das ações destes agentes, atingiu novos patamares, pois sob o óbice da moralização da sociedade, atacam-se as zungueiras e simbolicamente, tudo o que elas representam.

Elas são visadas diretamente por este projeto, porque representam, a face da pobreza que grassa o país, pois é dos bairros onde falta tudo, desde saneamento básico à segurança, de onde veem, empoeiradas, cansadas, pobres e doentes, mantendo atualizada uma imagem que a burguesia quer esquecer, ou substituir por uma face mais europeizada, se não branca, ao menos higienizada por uma estética que nega por si só, a realidade dos musseques. Que exclui pobres, mal vestidos, mal cheirosos, não falantes de um certo Português e por diante. Elas também representam uma ameaça, pois resistem há muito tempo às investidas do governo, bem como ao projeto neoliberal tropical, promovendo uma estratégia de subsistência que tem por base o trânsito irrestrito: elas rodam a cidade inteira, andam de uma ponta à outra, pelos próprios pés, misturam o espaço privado e o público e às vezes os tornam indistinguíveis porque andam com os bebês ao colo ou às costas, deitam na calçada para tirar um cochilo quando estão cansadas, fazem da rua a sua sala de visitas e enfim, sua casa.

Como eles atuam é descrito pelas mesmas:

O meu dia a dia de trabalho? ...tamo a tirar lá bocado, bocado, mas os comunitários sempre tão atrás de nós... ainda tá com as crianças a te darem queda, (...) é memo assim... E2

Os fiscais atuam memo, basta pegar o negocio já não te devolvem mais. E2

Os fiscais memo assim... Tás a ainda, tira o teu negócio na cabeça, assim corre, te dá queda, depois, você corre, sempre te segue, leva o teu negócio. Você não consegue fazer nada E2.

Aquele dinheiro quando já vem lá é bocado.

Vai salvar como o teu negócio? E o negócio alheio? Quase é nada! Aí a dona quero o dinheiro? Vai fazer como? O dinheiro vai tirar aonde? E3

Estão a apanhar memo, tão a agarrar e no conseguimo de vender. Não querem pra vendermos aqui na cidade E7

Contudo, elas já colonizaram as nossas cidades, são presença marcante na maior parte dos centros urbanos angolanos e o contingente de fiscalizadores do estado não é capaz por motivos óbvios (escassez de contingente humano e material) de fazer o tipo de repressão que se preconizou (sobretudo com a operação resgate). As zungueiras revindicam para si a cidade e o seu protagonismo na produção do espaço social urbano angolano, com a sua rotina de zunga.

Elas também contribuem na invenção de um espaço social novo nas cidades, um espaço que é o resultado da interação entre as estratégias e táticas como defende (QUEIROZ, 2016).

As zungueiras, estariam portanto, por meio de práticas quotidianas da zunga, criando novos espaços desconstruindo e reconstruindo as formas habituais de funcionamento dos lugares em que zungam. A simples passagem 
da zungueira seja numa rua do Lubango, de Luanda, do Huambo, ou de qualquer outra cidade, produz transformação do espaço.

Novas formas de se relacionar com aqueles lugares são portanto engendradas em meio à atividade da zungueira. Por um lado, a rua em que ela passa, transforma-se progressivamente num novo trajeto usado por outras zungueiras e de outro lado num lugar de referência para os moradores e outros transeuntes, que sabem que podem contar com os produtos da zunga. A palavra introduzida pelos pregões, altera a paisagem dentro dos bairros sobretudo periurbanos. Assim, o grito que anuncia a chegada do tomate, das couves, do peixe, etc. passa a ser parte daquela paisagem, e é diariamente esperado pelas donas de casa. Deste modo, o trânsito da zungueira, transforma a forma das pessoas de se relacionarem com aquele espaço, igualmente vai-se transformando consoante o produto que passa, o grito que se escuta. As hortaliças criam o reboliço que faz as donas de casas terem a curiosidade de espreitarem sobre os muros das casas para conferir a qualidade dos produtos.

A produção desse novo espaço social faz parte de um uso que essas mulheres fazem das condições que lhes são impostas pelo Estado, contrapondo a subjugação que se pretende delas, reescrevendo o espaço social e adotando-o também para si. Essa rebeldia da zungueira talvez possa ser justamente comparada ao exemplo de Certau (1990, p. 94), "uma criança ainda rabisca e suja o livro escolar; mesmo que receba um castigo por esse crime, a criança ganha um espaço, assina aí sua existência de autor”. É claro no caso da zungueira a situação é muito mais dramática, porém, sua atividade representa a subversão de uma racionalidade instituída pelo estado para a subalternizar. Desta forma, se do ponto de vista administrativo ela ainda assim é subalternizada, do ponto de vista cultural e simbólico, ela não o é com certeza.

Digamos que tudo passo, toda cidade mesmo passo. Rodo toda a cidade. Só paro mesmo se é para descansar E7.

Porque o negócio que eu levo.

Na cidade, é mais na cidade E9.

Na cidade, principalmente na cidade, e ou só na cidade, é a afirmativa da zunga. Para essa presença crescente das zungueiras, Santos (2011) chamou de zunguerização. Elas, por sua vez, resignadas ou não, "O que é que vamo fazer? E3", não pretendem abandonar a cidade.

A constante tensão entre zungueiras e fiscais é também um aspecto marcante e estressante da vida destas mulheres.

São perseguidas pelos agentes fiscais dos serviços comunitários não apenas por causa do carácter ilegal da atividade que desenvolvem, mas porque são vistas como uma agressão à estética da cidade. Se apanhadas, suas mercadorias são apreendidas sem possibilidade de reavê-las, ou destruídas no ato. A zungueira que perde toda a sua mercadoria tem que recomeçar do zero, os fiscais, hoje, tornam-se assim, parte do ônus da zunga.

Na zunga tem muito trabalho! os comunitários correm conosco, yá! Se te apanhar te levam o negócio, negócio não é nosso, é das Sras que abrem [fardo] só tiramo lá um bocadinho, que damo um 
bocadinho nos nossos filhos. E3

Os fiscais dão mesmo corrida, levam mesmo o negócio. Alguns pedem dinheiro, que é para darem o teu negócio, alguns levam mesmo assim, tem que começar mais de novo.

Não voltam mesmo, não dão, se calhar o negócio que está no cesto é só de 2000 kuanzas, eles pedem 3000, 5000 e num chega...E5

O problema é os fiscales que tá nos chatiar só, no temo lugar certo de vender, já não podem descansar, só fica toda hora. Nos dá só corrida. E6

Actuam, quando chegam de repente de carro, tiram o teu negócio, estão a pôr em cima do carro, então não tem como reagir, às vezes no negócio meteste lá negócio de 3000, vão te pedir lá mais de 3 só para você tirar o teu negócio... E6

Não vão te dar mais... aí só vão te pedir memo o pouco e às vezes vais preferir... só vale a pena abandoar lá a bacia e o negócio, para você amanhã ir lá caular outra coisa, com o dinheiro que você tens. E6

É difícil mais um pouco, já dá. É só ter cuidado com esses fiscais que querem reter o negócio das zungueiras digamos que eles vêem é só ter cuidado, até que não podem te agarrar... E7

Os comunitários dão corrida, a pessoa no sentam porque sai daí [menção à expulsão], porque é proibido vender ele não te dá o que é que tem não se interessa o que você faz, o mais importante é [dele]. E11

O espaço social criado pela zungueira, emerge também nessa interação tensa entre elas e os fiscais dos serviços comunitários. Aqueles para quem a burguesia terceiriza a tarefa de odiar as zungueiras. A este desafio se juntam o sofrimento diário pela dificuldade oferecida pelo trabalho que elas exercem.

Mas temo muito sofrimento aqui na zunga, $1^{a}$ coisa, você já não vende, nem nada, os comunitários também estão a agarrar, no temo negócio no temo trabalho nenhum, às vezes o governo ai apoiar vamo deixar de vender, vamo trabalhar. No temo trabalho nenhum. E2

$O$ trabalho da zunga é assim muito rijo nos dão corrida. A pessoa onde senta sempre nos dão corrida, não consegues vender à vontade, nos mercados no andas assim, devidamente, a gente tem que entrar assim na cidade, na zunga, mas sempre a gente aguentamo mesmo.

...Levam o negócio das pessoas, levam... até nem têm piedade, não querem saber se... levaste criança, se não levaste. O que eles querem é só mesmo levar o negócio. Levam na administração, o que você tem que fazer é preparar dinheiro para você ir buscar, mas só que o que eles pedem é muito caro, talvez o dinheiro que vão pedir lá, já podes comprar algo..., já pode comprar outra coisa... mas. E7

A referência ao sofrimento na zunga é recorrente e aparece em todas as entrevistas, se há algum prazer, com certeza há um sofrimento muito maior.

O trabalho da zunga é sofrimento, os fiscais a tua trás, você a correr, 
Dinâmicas Psicossociais do Trabalho das Zungueiras Angolanas

até ainda cais.

Tão sempre atrás das zungueiras.

Mas na praça o negócio assim não andam em condições. E8

Aí mesmo é que temo que lidar com os fiscais, os fis... todos os dias mesmo, os fiscais nos apanham, mas nós temo a le que... há fiscais que quando eles agarram, não entregam mais o negócio, que você pode ir lá, você ir encontrar.. eles arrecebem de forma... não de boa forma... E10

Sofrem memo, nós sofremo memo de verdade. E10

Um sofrimento que com os relatos não parece tão poético como a romantização que se faz da zunga no meio jornalístico, ou nas músicas.

\section{Não existe salvação para os pobres, uma luz no fim do túnel? Ou simplesmente cidadania?}

As zungueiras parecem depender apenas da solidariedade umas das outras e de suas parentes também na informalidade, mas a vontade de substituir a zunga por outra atividade, melhor remunerada e menos rude, é clara.

Assim vamo deixa de zunga e queremo trabalhar...

...o que aparecer. E1

...eu gostaria de deixar.. que um dos dia o governo vai nos recolher pra nos dar o emprego. Estamos muito cansada a zunga. Só das minhas pernas a doer, o corpo a doer, não tamo a consegui nada na vida, hoje vendemo um pouco, hoje no vendemo. E2

...é muito cansativo memo. E2

Têm a intuição de que o governo parece estar a faltar-lhes, mas não sabem muito bem porque sentem esse mal-estar.

O governo pensar nos ajudar um bocado para o nosso sofrimento ser normal... tamos a sofrer muito com a zunga.

O dinheiro não tá a aparecer sempre estamo a arrunhar, até na escola as pessoas estão a desconseguir as crianças para estudar. E6

Não se esquecem de ter seus próprios sonhos, sonhos que se articulam de novo com a intuição de que lhes falta alguma coisa que passa pela disponibilidade do estado.

O que eu quero para a minha vida? Quero um dia disse que o governo se pensar de entregar ao menos ai bilhete, cédula, para a pessoa já conseguir um trabalho, quando precisa um bilhete. E6

Coisas tão simples quanto, por exemplo, cidadania: um bilhete de identidade, uma cédula. Em suma, entendem, que ainda estão distantes de serem de fato cidadãs. 


\section{À guisa de considerações finais}

A análise feita não encerra as discussões, aliás, imaginamos que um retorno ao campo pode ainda ampliar nossos achados.

Para começar consideramos que o estabelecimento de categorias de análise para zunga é um importante resultado, na medida que permite que a mesma possa ser tratada de forma mais objectiva. Quanto ao conteúdo de tais categorias, sustentamos que ficou demonstrado que a zunga é uma espécie de tradição familiar, que infelizmente traz no seu bojo para as zungueiras como herança deste trabalho, a precariedade, o trabalho pesado e uma experiência continuada de pobreza e sofrimento intergeracional.

A zunga é usada de forma perniciosa para o aprisionamento cíclico de mulheres pobres, por meio de artifícios ilegais tais como a cobrança abusiva de juros, a consignação de mercadorias sem nenhum tipo de garantia para as zungueiras e um empreendedorismo predatório, que as escraviza, exploração muitas vezes levada a cabo por familiares próximos. Ela encerra o paradoxo de que ao lado de toda essa vivência perversa parece ser também, para muitas o caminho para a sua emancipação.

A zunga constrói um novo espaço social e a articulação produzida pela zungueira para que tal aconteça por meio do uso de pregões, como o famoso 'arreiou, arreiou!', técnica usada para tentar atrair clientes e melhorar o rendimento, pela mobilidade livre e quase irrestrita, etc, coisas que causam o incômodo que parece reacender a raiva burguesa contra a zungueira.

A zunga deve ser vista de forma ampla, como impulsionadora da criação de novos espaços sociais, redefinindo a paisagem social, econômica, cultural e política do país, fugindo-se da percepção dela como um problema, evitando que tal visão se torne num impasse para qualquer estratégia de governo que deseje abordar esta questão objetivamente.

\section{Referências}

AFONSO, A. \& CAETANO, C. Diagnóstico de gênero em Angola. União Europeia, 2015.

COSTA, F. T. B.; JUSTO, S. J. \& FREITAS, C. J. De. Paradoxos do trabalho no capitalismo contemporâneo. Argumentum, Vitória (ES), v. 8, n.1, p. 100114, jan./abr, 2016.

\section{INSTITUTO NACIONAL de ESTATÍSTICA. Inquérito Integrado Sobre o Bem Estar da População. INE, 2013.}

LIBERATO, E. 40 anos de independência. Uma reflexão em torno da condição da mulher angolana. Estudos feministas, v. 24, n. 3, p. 997 - 1006, 2016.

LOPES, C. M. Roque santeiro. Entre a ficção e a realidade. Estoril: Princípia Editora, 2007. 
Dinâmicas Psicossociais do Trabalho das Zungueiras Angolanas

PANTOJA, S. A. Imagens e Perpectivas Culturais: o trabalho feminino nas feiras e mercados luandenses. In: SARMENTO, Clara. (Org.). Condição feminina no Império colonial português. Porto: Politema, 2008.

PEREIRA, A. Desenvolvimento de políticas públicas para a inserção da mulher angolana no mercado de trabalho. Conselho para o Desenvolvimento da Pesquisa em Ciências Sociais em África. 11 ${ }^{\text {a }}$ Assembleia-Geral: Repensando o desenvolvimento Africano: Além do Impasse, Rumo às Alternativas, 2015.

QUEIROZ, L. H. C. R. de. Entre legados coloniais e agências: as zungueiras na produção do espaço urbano da Luanda. 2016. Dissertação (Mestrado em Desenvolvimento, Sociedade e Cooperação Internacional) Universidade de Brasília, Brasília.

SANTOS, O. Mamãs quitandeiras, kinguilas e zungueiras: Trajetórias femininas no comércio de rua em Luanda. Historien. Revista de História, v. 4, p. $35-61,2011$.

SATO, L.; SOUZA, M. P. R. de. A Contribution Towards Revealing the Complexity of the Everyday life by Means of the Ethnographic Research in Psychology. Psicologia USP, v. 12, n. 2, p. 29 - 47, 2001.

Nota da autoria Meus profundos agradecimentos ao Nuno Barreto e Vanusa Incha que me deram todo o suporte técnico no trabalho de campo, ao professor José Sterza Justo e ao companheiro de trabalho Cledione Jacinto de Freitas que com suas sugestões ajudaram a melhorar substancialmente o artigo.

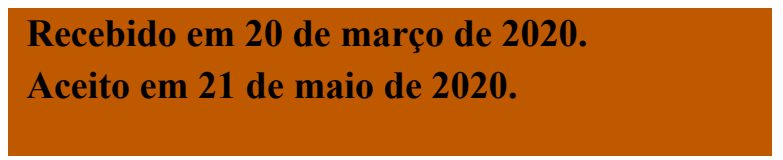

Felizardo Tchiengo Bartolomeu Costa 